\title{
FITOTECNIA
}

\section{SISTEMAS DE MANEJO DE PLANTAS DANINHAS NO DESENVOLVIMENTO E NA PRODUTIVIDADE DA SOJA ( $\left.{ }^{1}\right)$}

\author{
JAMIL CONSTANTIN $\left({ }^{2}\right)$; RUBEM SILVÉRIO DE OLIVEIRA JÚNIOR $\left({ }^{2 *}\right)$; MIRIAM HIROKO INOUE $\left({ }^{3}\right)$; \\ SIDNEY DOUGLAS CAVALIERI $\left({ }^{4}\right)$; JOÃO GUILHERME Z. DE ARANTES $\left({ }^{4}\right)$
}

\begin{abstract}
RESUMO
A escolha do momento adequado para a dessecação da cobertura vegetal antecedente à semeadura é fundamental para o êxito da cultura da soja cultivada no sistema de plantio direto. Neste contexto, o objetivo do trabalho foi o de avaliar dois sistemas de manejo de plantas daninhas: imediatamente antes da semeadura (sistema "Aplique-Plante" - AP) e o manejo antecipado (MA), composto por duas aplicações. No MA, a primeira aplicação de glyphosate (1240 $\left.\mathrm{g}^{-1} \mathrm{ha}^{-1}\right)$ foi entre 30 e 35 dias antes da semeadura da cultura, e a segunda às vésperas da semeadura. Para o AP, as aplicações com 1.080 a $1.260 \mathrm{~g} \mathrm{ha}^{-1}$ de glyphosate foram realizadas 48 horas antes da semeadura. Os trabalhos foram desenvolvidos na safra 2003/2004, em seis localidades no Estado do Paraná: Sertãozinho, Campo Mourão, Iretama, Pitanga, Boa Esperança e Mamborê, em áreas com grande densidade de infestação de plantas daninhas antes da semeadura direta da soja. Foram realizadas avaliações referentes ao controle das plantas daninhas e desenvolvimento e produtividade da cultura. Com a utilização do MA foi proporcionado maior controle das plantas daninhas após a emergência da cultura. As plantas de soja nas áreas $\mathrm{AP}$ estavam com menor altura, em comparação às no MA, evidenciando-se atraso no crescimento. Verificou-se redução de produtividade em todas as localidades onde se adotou o manejo AP, com reduções entre $15 \%$ e $50 \%$.
\end{abstract}

Palavras-chave: dessecação, Glycine max, plantas daninhas, manejo integrado, semeadura direta.

\section{ABSTRACT \\ BURNDOWN SYSTEMS ON GROWTH AND GRAIN YIELD IN SOYBEANS IN PARANÁ STATE, BRAZIL}

\begin{abstract}
The choice of the adequate moment for the desiccation of the green cover that precedes the sowing is fundamental for the success of no-till soybeans. This context, the work was aimed to study two burndown systems: desiccation immediately before sowing (AP) and anticipated desiccation (MA), composed by two burndown herbicide applications. For MA, the first application of glyphosate $\left(1240 \mathrm{~g} \mathrm{ha}^{-1}\right)$ occurred between 30 and 35 days before the sowing of the crop, and the second was done just before sowing. For AP, the applications (1080 to $1260 \mathrm{~g} \mathrm{ha}^{-1}$ of glyphosate) occurred within 48 hours prior to sowing. The trials were developed in 2003/2004 growing season, in six localities in Paraná State: Sertãozinho, Campo Mourão, Iretama, Pitanga, Boa Esperança, and Mamborê, in areas with high density of weeds preceding no-till soybean sowing. Evaluations related to weed control and soybean development and grain yield were performed. MA burndown systems provided improved control of weeds after crop emergence. Soybean plants from AP areas were shorter, in comparison to ME, evidencing a delay in the shoot growth. Reduction of grain yield was verified for all localities when AP burndown system was adopted, with reductions between $15 \%$ and $50 \%$.
\end{abstract}

Key words: desiccation, Glycine max, weeds, integrated management, no-till.

$\left(^{1}\right)$ Recebido para publicação em 22 de fevereiro de 2007 e aceito em 30 de julho de 2008.

$\left({ }^{2}\right)$ Departamento de Agronomia, Universidade Estadual de Maringá (UEM). Av. Colombo, 5790, Bl 32, 87020-900 Maringá (PR). E-mail: rsojunior@uem.br. $\left(^{*}\right)$ Autor correspondente.

$\left({ }^{3}\right)$ Departamento de Agronomia, Universidade do Estado de Mato Grosso (UNEMAT), Caixa Postal 287, 78300-000 Tangará da Serra (MT). E-mail: miriamhinoue@hotmail.com

$\left({ }^{4}\right)$ Engenheiro Agrônomo, Aluno do curso de Pós-Graduação em Agronomia (UEM). 


\section{INTRODUÇÃO}

Uma das formas mais comuns de se realizar o manejo inicial das plantas daninhas é a aplicação de dessecantes por volta de dez dias antes da semeadura. No entanto, com este sistema podem-se ter problemas como rebrotas e emergência de um novo fluxo proveniente do banco de sementes do solo, com o qual se pode ter interferência no estabelecimento, desenvolvimento inicial e rendimento final da cultura, devido à vantagem competitiva no estabelecimento anterior das plantas daninhas. Segundo Oliveira JúNIOR et al. (2006), uma alternativa bastante utilizada é a aplicação do herbicida sistêmico, normalmente glyphosate, imediatamente antes da semeadura, em operação rotineiramente chamada de "Aplique-Plante" (AP).

Em alguns trabalhos, tem sido demonstrado que, com aplicações seqüenciais antecipadas de herbicidas sistêmicos, como glyphosate, e após 10 a 20 dias, na véspera ou na data da semeadura e herbicidas de contato como paraquat, paraquat+diuron ou diquat, proporciona-se maior eficiência no controle das plantas daninhas, possibilitando a semeadura no limpo (Procópio et al., 2006). A segunda aplicação serve fundamentalmente para a correção de problemas de rebrotas e de novos fluxos de plantas daninhas já emergidas por ocasião da semeadura (MAROCHI, 1996; PINTO et al., 1997). Uma vantagem adicional é o fato de que espécies de difícil controle como Ipomoea grandifolia e Comelina benghalensis podem ser adequadamente controladas. De acordo com Oliveira Júnior. et al. (2006), dessecações seqüenciais são recomendadas, principalmente, em condições de altas infestações ou para plantas daninhas consideradas de difícil controle.

O manejo no plantio direto é importante, não só para que a cultura inicialmente esteja sem a interferência das plantas daninhas, mas também, pode ser decisivo para determinar o adequado funcionamento dos herbicidas utilizados após a emergência da cultura. Caso não seja eficiente, podem ocorrer rebrotas e intensa infestação da área, com dificuldades à ação de herbicidas utilizados após a semeadura da cultura. Atente-se para o intervalo entre a dessecação e o plantio das culturas porque, em áreas com intensa cobertura vegetal (acima de $40 \%$ a $50 \%$ de cobertura do solo), onde as culturas estão sendo instaladas em períodos muito curtos após a operação de dessecação, verificam-se plantas com clorose nas folhas, estiolamento no período inicial e redução no desenvolvimento vegetativo posterior, podendo haver inclusive consequência negativa na produtividade (CAlegari et Al., 1998; Constantin et al., 2007).
Peixoto et al. (2000) verificaram que a produtividade da soja foi diminuída em até 13,9\%, quando semeada imediatamente após a dessecação de sorgo. Melhorança e Vieira (1999) observaram que rendimento e desenvolvimento vegetativo da soja foram prejudicados, conforme a época de dessecação de Brachiaria decumbens; com a dessecação realizada aos 18 dias antes da semeadura propiciou-se rendimento de $17 \%$ e $32 \%$ maiores do que com dessecações realizadas, respectivamente, aos sete e um dia antes da semeadura. Evidencia-se, então, que nas áreas de plantio direto cuja cobertura vegetal geralmente está em grande quantidade, a dessecação deve ser feita no mínimo 15 a 20 dias antes da semeadura, a fim de se evitar possíveis prejuízos à produtividade (OliveIRA JúnIOR et al., 2006; CONSTANTIN et al., 2007).

Adicionalmente, com a dessecação antecipada podem ser constatados outros benefícios, como mais eficiência e rendimento na operação de semeadura, menos infestação nas culturas estabelecidas em sucessão e mais eficácia dos herbicidas aplicados após a emergência (OliveIRA JúNIOR et al., 2006).

O objetivo deste trabalho foi definir, entre os dois avaliados, o manejo mais adequado das plantas daninhas antecedendo a semeadura direta da soja, em diferentes localidades com grande densidade de infestação.

\section{MATERIAL E MÉTODOS}

O experimento foi desenvolvido em seis localidades no Centro-Oeste do Estado do Paraná, nos municípios de Sertãozinho, Campo Mourão, Iretama, Pitanga, Boa Esperança e Mamborê. Todas as áreas haviam sido cultivadas com aveia preta (Avena strigosa). Nos experimentos, foram avaliados dois sistemas de manejo de plantas daninhas, sendo um proposto: Sistema de Manejo Antecipado de Controle de Plantas Daninhas (MA) e o outro adotado pelo produtor denominado Aplique-Plante (AP).

As parcelas experimentais tinham dimensões de $10,8 \mathrm{~m}$ de largura $\times 50,0 \mathrm{~m}$ de comprimento, adotando-se como área útil as dez linhas centrais, exceto 10 metros em cada extremidade.

Os tratamentos avaliados consistiram basicamente na combinação dos dois sistemas de

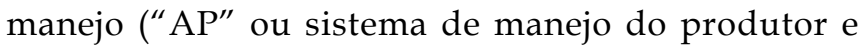
"MA", ou sistema de manejo antecipado proposto) com seis localidades. $\mathrm{O}$ delineamento experimental utilizado foi em blocos casualizados com seis repetições, em que cada localidade constituiu-se de ensaio individual. 
No início da adoção do MA nas diferentes propriedades, as áreas estavam com valores de cobertura de solo variáveis de $50 \%$ a $70 \%$ (Tabela 1). Em todos os locais, a primeira aplicação de herbicidas foi entre 30 e 35 dias antes da semeadura, e a segunda, um pouco antes da semeadura. Por outro lado, o tratamento-padrão dos produtores, constando de 1.080 a $1.260 \mathrm{~kg} \mathrm{ha}^{-1}$ e.a de glyphosate, foi aplicado nas 48 horas anteriores à semeadura, em todas as propriedades. Em todas as localidades, no manejo "padrão" foi reproduzido o sistema de manejo adotado em toda a propriedade. As áreas estavam com infestação diversificada (Tabela 1).

Após a emergência da soja em cada uma das áreas, nas parcelas referentes ao manejo $\mathrm{AP}$, adotouse o mesmo controle de plantas daninhas do restante da respectiva propriedade, isto é, foi estabelecido em função da experiência do produtor. As alternativas de controle em pós-emergência foram variáveis, constando de adoção de aplicações únicas de herbicidas em pós-emergência, de aplicação seqüencial e, ou de mistura de herbicidas e, podendo, em função da necessidade, aplicação ou não de um herbicida específico para o controle de gramíneas. As informações sobre a infestação da área após a semeadura da cultura, as modalidades de controle adotadas, os herbicidas utilizados, as doses e datas das respectivas aplicações estão relacionadas na tabela 2. Nas parcelas referentes ao MA adotou-se, como padrão, a aplicação seqüencial em pósemergência e, como referência para o momento de aplicação, o estádio de duas folhas verdadeiras das folhas largas na área.

Os produtos a serem utilizados nos sistemas de manejo e nas aplicações em pós-emergência foram escolhidos em função da composição da infestação na área e da sua representatividade em termos de importância no mercado de herbicidas para a cultura da soja.

Em todas as áreas, a semeadura direta foi realizada no espaçamento de $0,45 \mathrm{~m}$ entre linhas e com 14 a 18 sementes por metro linear na safra 2003/ 2004. Os demais tratos culturais foram realizados segundo as recomendações regionais (EMBRAPA SoJA, 2003) e realizados simultaneamente nos dois sistemas de manejo em cada área.

Todas as aplicações de herbicidas foram realizadas com pulverizador costal de pressão constante, à base de $\mathrm{CO}_{2}$, equipado com pontas tipo leque XR-110.02, pressão de $2,0 \mathrm{kgf} \mathrm{cm}{ }^{-2}$, com o equivalente a $200 \mathrm{~L} \mathrm{ha}^{-1}$ de calda. Em todas as aplicações, tanto nas de manejo quanto nas de pósemergência, as condições climáticas estavam adequadas, ou seja, UR ar $\geq 55 \%$; temperatura $\leq 30$ ${ }^{\circ} \mathrm{C}$, além do solo úmido.

\section{As características avaliadas foram:}

a) Plantas daninhas controladas no manejo em pré-semeadura: porcentagens de controle de plantas daninhas no manejo com base em escala visual de 0 a $100 \%$ (Sociedade Brasileira da CiênCia das Plantas DANINHAS, 1995), com avaliações realizadas na data da semeadura, aos 7 e 14 dias depois da semeadura (DDS).

b) Plantas daninhas controladas em pósemergência: porcentagem de controle, segundo escala de avaliação visual de 0 a $100 \%$ (SOCIEDADE Brasileira da Ciência das Plantas Daninhas, 1995), entre 46 e 53 DDS.

c) Número de plantas daninhas: contagens realizadas na véspera da semeadura e durante o ciclo da cultura, antes de cada aplicação de herbicidas em pós-emergência e após as aplicações dos pósemergentes. Em cada avaliação, foram realizadas vinte amostragens por parcela, realizada em uma área de $0,5 \times 0,5 \mathrm{~m}$ (Sociedade Brasileira da Ciência das Plantas DANINHAS, 1995).

d) Na cultura da soja: estande (número médio de plantas em cinco amostragens de dois metros lineares na área útil das parcelas) aos 38 DDS; altura das plantas do solo até a inserção da última folha completamente expandida em 50 plantas por parcela aos 38 DDS e na data da colheita em cada área; porcentagem de cobertura do solo - "fechamento", por meio de análise visual aos 38 e 52 DDS; número de vagens por planta em 50 plantas escolhidas aleatoriamente na área útil de cada parcela por ocasião da colheita; produtividade de grãos em seis amostras por parcela, sendo cada uma determinada em cinco linhas de quatro metros na área útil de cada parcela, com posterior trilha mecânica em trilhadora estacionária e limpeza manual; teor de água nos grãos colhidos em duas amostras por parcela e massa de mil grãos em cinco amostras por parcela.

Os dados foram submetidos à análise de variância para cada localidade. Em seguida, procedeuse a análise conjunta das seis localidades, uma vez que a razão entre o maior e o menor quadrado médio residual foi superior a sete (BANZATTO e KRONKA, 1995). Quando a interação (sistemas de manejo $x$ localidades) foi significativa $(\mathrm{P}<0,05 \%)$, procederam-se os desdobramentos necessários, sendo as médias comparadas pelo teste de Tukey a $5 \%$ de probabilidade, utilizando-se o pacote estatístico SAEG (SAEG, 1997). 


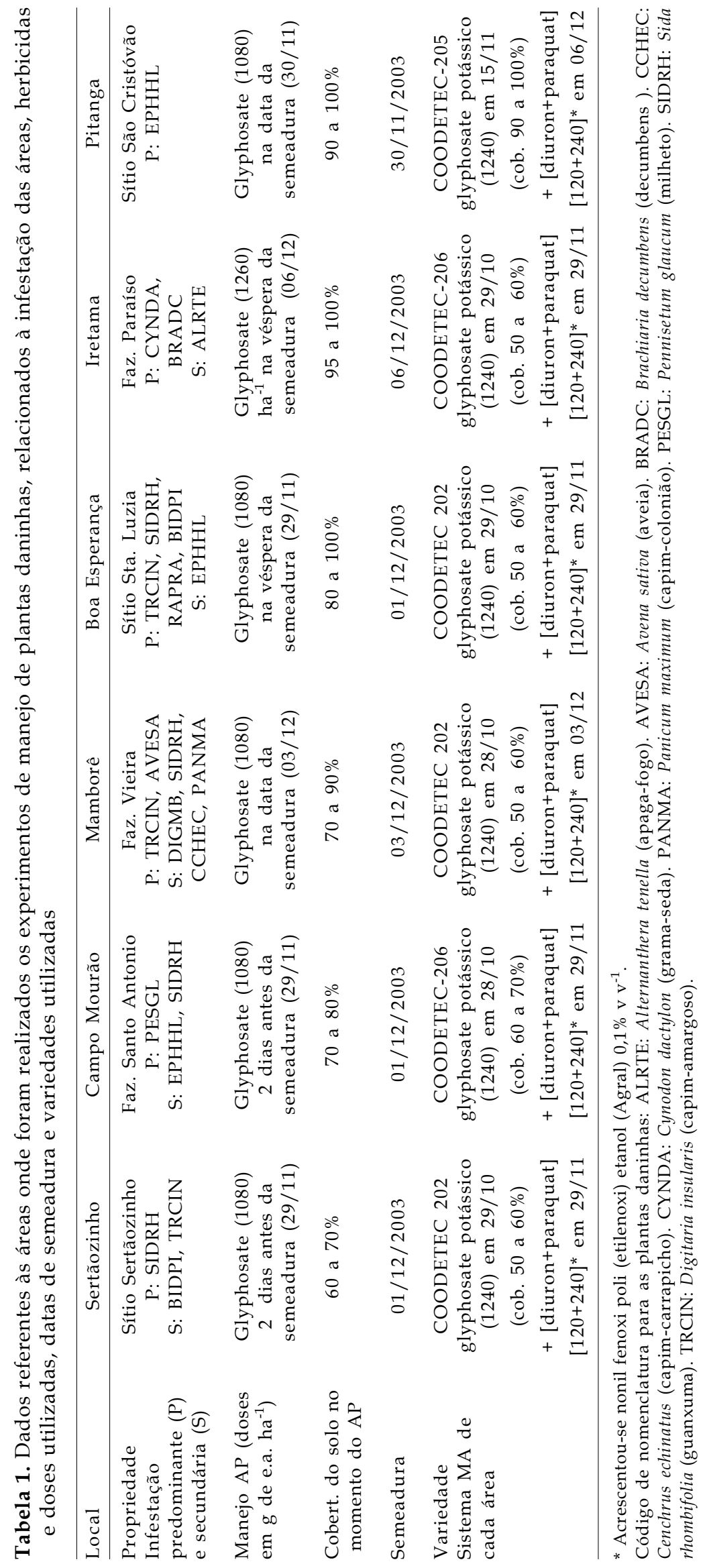




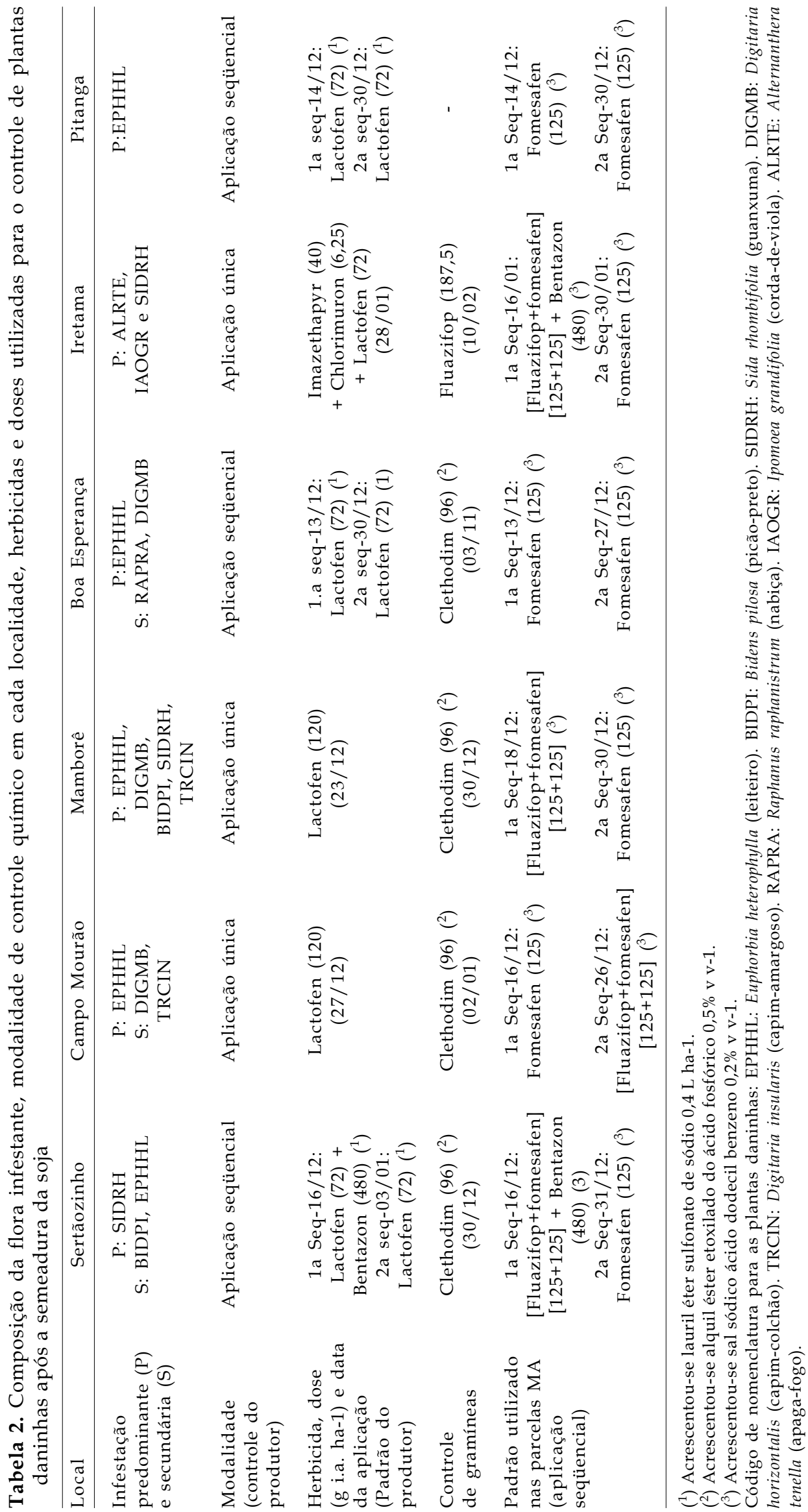




\section{RESULTADOS E DISCUSSÃO}

No sistema MA foram proporcionados níveis de controle da infestação significativamente maiores aos daqueles no manejo AP, utilizado tradicionalmente pelos agricultores (Figura 1). Tal situação é consequiência das duas aplicações de herbicidas antes da semeadura, comparadas à aplicação única no manejo AP. Embora haja um gasto adicional em termos de custos relacionados aos herbicidas e à aplicação em si, com o MA evita-se a interferência das plantas daninhas na soja, desde o momento da semeadura. Embora no sistema AP tenda à melhoria com o decorrer do tempo, não se constata igualdade de eficácia quanto ao MA no início do ciclo da cultura. É possível que essa melhoria seja decorrente da presença de espécies menos susceptíveis ao glyphosate, ou ao fato da aplicação de um herbicida sistêmico como o glyphosate ser imediatamente seguida da movimentação das semeadoras de plantio direto na área. Desse modo, pode ser promovido, pelo menos na linha de semeadura, algum nível de controle mecânico das plantas daninhas pela passagem dos discos de plantio; embora possa ser auxiliar ao controle químico, o corte das plantas daninhas pelos discos de plantio pode ser uma interrupção na translocação do herbicida, especialmente importante para o controle de espécies perene presentes nas áreas avaliadas, como Brachiaria decumbens e Cynodon dactylon. Além do fato do controle da biomassa presente ser superior com a adoção do MA, verifica-se também que, mesmo com níveis aceitáveis de controle após 14 DDS, no manejo AP ainda se tem elevado nível de sombreamento durante a emergência da soja e nos primeiros dias de crescimento, em função da velocidade de dessecação do glyphosate, com reflexos posteriores no desenvolvimento da cultura. Tais constatações também foram verificadas nos trabalhos de Constantin et al. (2000) e de Oliveira Júnior et al. (2006).

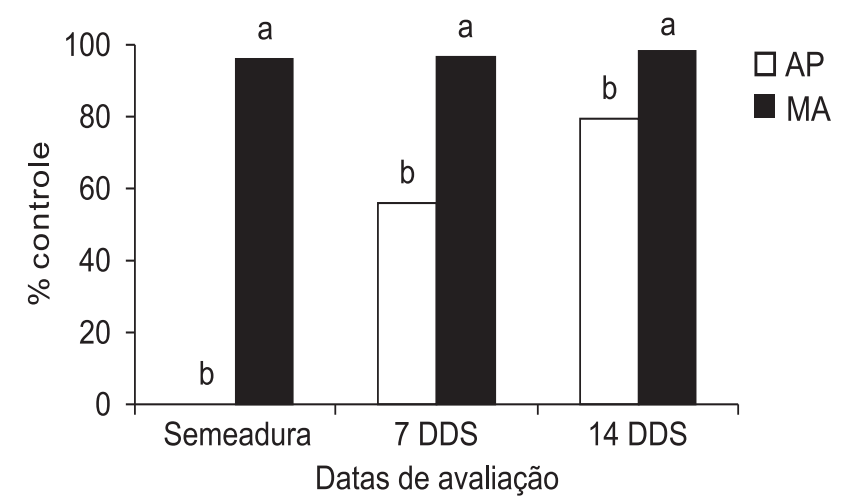

Figura 1. Porcentagens (médias de seis localidades) de controle de plantas daninhas nos sistemas de manejo Aplique-Plante (AP) e Antecipado (MA), na data da semeadura e em duas datas depois da semeadura (DDS). Estado do Paraná, em dez./2003. Média seguida pelas mesmas letras dentro de cada data de avaliação não são diferentes entre si pelo teste de Tukey (5\%).
Na data da semeadura, a quantidade de plantas daninhas emergidas foi sempre superior no sistema MA (Tabela 3). Esse fato se deve às condições estabelecidas para tal visto que, com a dessecação antecipada é favorecido o estabelecimento de cobertura completamente dessecada antes da semeadura e consequentemente, a emergência de novas plantas daninhas. O objetivo do sistema é justamente este, pois assim pode-se eliminar grande parte das plantas daninhas com possível emergência após a semeadura da cultura, o que foi obtido com a aplicação de paraquat+diuron imediatamente antes da semeadura e ainda serem controladas possíveis rebrotas remanescentes da primeira aplicação, como relatado por Marochi (1996), Pinto et al. (1997) e MelhorançA et al. (1998). O reflexo pode ser constatado durante o ciclo da cultura, quando a situação se inverte, com menores densidades de plantas daninhas no manejo MA em relação ao sistema AP, resultando, em média, em redução de $41,4 \%$ no número de plantas daninhas no sistema MA (Tabela 3), ou seja, o equivalente a menos 108,3 plantas por metro quadrado. Os benefícios de menos infestação são, principalmente, o de se evitar interferência precoce na cultura, com comprometimento à sua produtividade e, ainda o estabelecimento de condições para um funcionamento mais adequado dos herbicidas aplicados após a emergência da soja. Com a adoção do sistema MA, proporcionou-se uma tendência de mais controle de plantas daninhas, após a emergência da cultura (Tabela 4).

O primeiro efeito negativo do manejo AP na soja é a redução do estande da cultura, em função de mais dificuldade de trabalho da semeadora. Dependendo da cobertura do solo e da biomassa presente, tais dificuldades podem ser repercutidas não só na eficiência da semeadora, mas também no rendimento do trabalho e nos custos de manutenção dos implementos (Oliveira Júnior et al., 2006). Além disso, a presença de densa biomassa também pode ser impedimento mecânico à emergência da cultura. Neste trabalho, em apenas uma das localidades estudadas houve redução significativa no estande, que foi em Boa Esperança (Tabela 5).

É possível observar o efeito significativo dos sistemas de manejo na altura de plantas de soja aos 38 DDS, sendo negativo o do manejo AP no crescimento da cultura (Tabela 6). No desdobramento da interação, a altura das plantas foi reduzida no manejo AP, nas localidades de Boa Esperança e Pitanga, ou seja, em um terço das áreas avaliadas. Com o decorrer do ciclo, os efeitos negativos desse manejo refletiram-se no menor tamanho da soja, em relação ao sistema MA, em todas as áreas avaliadas (Tabela 7). 
Tabela 3. Densidade de plantas daninhas na data da semeadura e durante o ciclo da soja nos sistemas de manejo Aplique-Plante (AP) e Manejo Antecipado (MA), em diferentes localidades do Estado do Paraná, em dez./2003 a mar./2004

\begin{tabular}{|c|c|c|c|c|}
\hline \multirow{2}{*}{ Localidade } & \multicolumn{2}{|c|}{ Na data da semeadura } & \multicolumn{2}{|c|}{ Durante o ciclo } \\
\hline & $\mathrm{AP}$ & MA & $\mathrm{AP}$ & MA \\
\hline & & +2 & & \\
\hline 1. Sertãozinho & $150,00 \mathrm{~b}$ & $226,00 \mathrm{a}$ & 289,83 & $235,00 \mathrm{~b}$ \\
\hline 2. Campo Mourão & $20,00 \mathrm{~b}$ & 76,50 a & 129,84 & $35,84 \mathrm{~b}$ \\
\hline 3. Mamborê & $12,00 \mathrm{~b}$ & 48,80 a & 92,00 & $56,49 \mathrm{~b}$ \\
\hline 4. Boa Esperança & $64,00 \mathrm{~b}$ & $500,00 \mathrm{a}$ & 504,84 & $291,51 \mathrm{~b}$ \\
\hline 5. Iretama & $60,40 \mathrm{~b}$ & $630,00 \mathrm{a}$ & 122,40 & $66,00 \mathrm{~b}$ \\
\hline 6. Pitanga & $29,20 \mathrm{~b}$ & 134,40 a & 441,80 & $225,97 \mathrm{~b}$ \\
\hline Médias & $55,93 \mathrm{~b}$ & 269,28 a & 261,79 & $153,47 \mathrm{~b}$ \\
\hline $\mathrm{CV}(\%)$ & & & & \\
\hline
\end{tabular}

Em cada linha, médias seguidas pelas mesmas letras, em cada data de avaliação não são diferentes entre si pelo teste de Tukey (5\%).

Tabela 4. Controle de plantas daninhas após a emergência da soja nos sistemas de manejo Aplique-Plante (AP) e Manejo Antecipado (MA), em diferentes localidades do Estado do Paraná, em dez./2003 a mar./2004

\begin{tabular}{lrrcc}
\hline \multirow{2}{*}{ Localidade } & \multicolumn{3}{c}{ Sistema de manejo } & Avaliação \\
\cline { 2 - 4 } & \multicolumn{2}{c}{ AP } & MA & DDS \\
\cline { 2 - 4 } 1. Sertãozinho & 96,7 a & 98,2 a & 53 \\
2. Campo Mourão & 93,0 a & 99,0 a & 53 \\
3. Mamborê & 57,0 b & 92,0 a & 50 \\
4. Boa Esperança & 95,0 a & 97,0 a & 52 \\
5. Iretama & 88,0 b & 96,0 a & 52 \\
6. Pitanga & 82,0 b & 99,0 a & - \\
\hline Médias & 85,3 b & 96,9 a & - \\
CV $\%)$ & 18,3 & - & \\
\hline
\end{tabular}

Em cada linha, médias seguidas pelas mesmas letras não são diferentes entre si pelo teste de Tukey (5\%).

DDS: Dias depois da semeadura.

Tabela 5. Estande de soja aos 38 dias depois da semeadura submetida aos dois sistemas de manejo de plantas daninhas Aplique-Plante (AP) e Manejo Antecipado (MA), em diferentes localidades do Estado do Paraná, em dez./2003 a mar./2004

\begin{tabular}{|c|c|c|c|}
\hline \multirow{2}{*}{ Localidade } & \multicolumn{2}{|c|}{ Sistema de manejo } & \multirow{2}{*}{ Médias } \\
\hline & $\mathrm{AP}$ & MA & \\
\hline & & plantas $\mathrm{n}$ & \\
\hline 1. Sertãozinho & 11,77 a & 12,40 a & 12,09 \\
\hline 2. Campo Mourão & 14,60 a & 15,63 a & 15,12 \\
\hline 3. Mamborê & 12,03 a & 11,13 a & 11,58 \\
\hline 4. Boa Esperança & $13,40 \mathrm{~b}$ & $15,80 \mathrm{a}$ & 14,60 \\
\hline 5. Iretama & 9,63 a & 9,17 a & 09,40 \\
\hline 6. Pitanga & $12,93 \mathrm{a}$ & 12,35 a & 12,64 \\
\hline Médias & 12,39 a & 12,75 a & - \\
\hline $\mathrm{CV}(\%)$ & 10,0 & - & - \\
\hline
\end{tabular}

Em cada linha, médias seguidas pelas mesmas letras não são diferentes entre si pelo teste de Tukey (5\%). 
Tabela 6. Altura de plantas de soja aos 38 dias depois da semeadura submetida aos dois sistemas de manejo de plantas daninhas Aplique-Plante (AP) e Manejo Antecipado (MA), em diferentes localidades do Estado do Paraná, em dez./ 2003 a mar./ 2004

\begin{tabular}{|c|c|c|c|}
\hline \multirow{2}{*}{ Localidade } & \multicolumn{2}{|c|}{ Sistema de manejo } & \multirow{2}{*}{ Médias } \\
\hline & $\mathrm{AP}$ & MA & \\
\hline & & $\mathrm{cm}-$ & \\
\hline 1. Sertãozinho & 20,23 a & 21,60 a & 20,92 \\
\hline 2. Campo Mourão & 25,83 a & 25,79 a & 25,81 \\
\hline 3. Mamborê & 16,83 a & 16,48 a & 16,66 \\
\hline 4. Boa Esperança & $21,75 \mathrm{~b}$ & 25,05 a & 23,40 \\
\hline 5. Iretama & 15,45 a & 15,20 a & 15,33 \\
\hline 6. Pitanga & $11,55 \mathrm{~b}$ & 18,13 a & 14,84 \\
\hline Médias & $18,61 \mathrm{~b}$ & 20,38 a & - \\
\hline $\mathrm{CV}(\%)$ & 9,0 & - & - \\
\hline
\end{tabular}

Em cada linha, médias seguidas pelas mesmas letras não são diferentes entre si pelo teste de Tukey (5\%).

Tabela 7. Altura de plantas de soja submetidas a dois sistemas de manejo Aplique-Plante (AP) e Manejo Antecipado (MA), em diferentes localidades, do Estado do Paraná, por ocasião da colheita, em dez./2003 a mar./2004.

\begin{tabular}{|c|c|c|c|}
\hline \multirow{2}{*}{ Localidade } & \multicolumn{2}{|c|}{ Sistema de manejo } & \multirow{2}{*}{ Médias } \\
\hline & $\mathrm{AP}$ & MA & \\
\hline & & & \\
\hline 1. Sertãozinho & $58,60 \mathrm{~b}$ & 64,78 a & 061,69 \\
\hline 2. Campo Mourão & $63,91 \mathrm{~b}$ & 72,30 a & 068,11 \\
\hline 3. Mamborê & $70,00 \mathrm{~b}$ & 75,38 a & 072,69 \\
\hline 4. Boa Esperança & $43,00 \mathrm{~b}$ & 62,61 a & 052,81 \\
\hline 5. Iretama & $65,72 \mathrm{~b}$ & 79,81 a & 072,77 \\
\hline 6. Pitanga & $97,90 \mathrm{~b}$ & 109,00 a & 103,45 \\
\hline Médias & $66,52 \mathrm{~b}$ & 77,31 a & - \\
\hline $\mathrm{CV}(\%)$ & 5,5 & - & - \\
\hline
\end{tabular}

Em cada linha, médias seguidas pelas mesmas letras não são diferentes entre si pelo teste de Tukey (5\%).

O efeito inibitório no crescimento da cultura foi variável entre 7,1\% (Mamborê) e 31,3\% (Boa Esperança). Com o menor tamanho das plantas pode ser comprometida a capacidade competitiva da soja em relação à interferência estabelecida por plantas daninhas, insetos e doenças, assim como reduzido o potencial produtivo em função da menor área fotossintetizante e do menor número de estruturas reprodutivas. Uma possível explicação para tal fato é que a cultura, nas áreas de manejo AP, inicialmente se desenvolveu em condição de grande quantidade de biomassa e de intenso sombreamento, resultando-se em estiolamento. Dessa forma, há grande gasto energético no início do ciclo da cultura, com o que pode ter sido comprometido seu desenvolvimento posterior (CALEGARI et al., 1998).
O efeito dos sistemas de manejo na altura das plantas refletiu-se também na capacidade de sombreamento do solo, fato decisivo na competitividade da cultura frente dos novos fluxos de emergência de plantas daninhas.

Aos 38 DDS as áreas com MA estavam, em média, com $81 \%$ de "fechamento", ao passo que, aquelas com AP estavam apenas com 56\% (Figura 2). Na segunda avaliação, realizada aos 52 DDS, com MA o fechamento era praticamente total $(97 \%)$, contra apenas $81 \%$ em média no AP. O valor aos 53 DDS para o AP é justamente aquele "determinado" no sistema MA, aos 38 DDS, o que implica dizer que nas plantas das áreas com $\mathrm{AP}$ o atraso no crescimento era equivalente a 14 dias. 


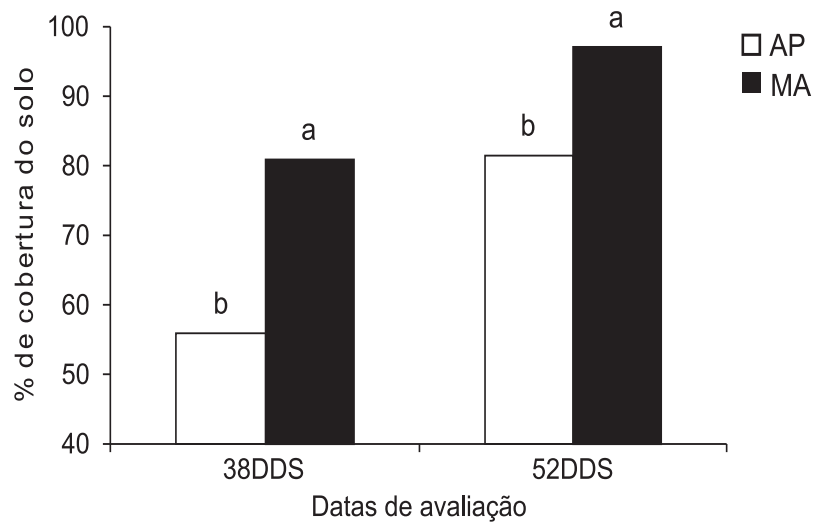

Figura 2. Porcentagem de cobertura do solo por plantas de soja em sistemas de manejo Aplique-Plante (AP) e Antecipado (MA), em duas datas depois da semeadura (DDS). Estado do Paraná, em dez./2003 a jan./2004. Média seguida pelas mesmas letras dentro de cada data de avaliação não são diferentes entre si pelo teste de Tukey (5\%).
Com a utilização do manejo AP, foi negativamente afetado o número de vagens por planta, na localidade de Boa Esperança (Tabela 8), provavelmente em função dos efeitos anteriormente discutidos em relação ao crescimento das plantas. Por outro lado, em Sertãozinho, com o manejo AP foi proporcionado maior número de vagens por planta em relação ao MA.

No entanto, tal incremento, neste componente da produtividade, não foi refletido em aumento na produtividade, possivelmente pelo efeito depressor do manejo AP em outros componentes da produtividade. Especificamente, nessa última localidade, foi a massa de mil grãos um dos componentes em que se constatou efeito inverso, isto é, de redução com a utilização do manejo AP (Tabela 9).

Tabela 8. Número de vagens de soja submetida a dois sistemas de manejo de plantas daninhas Aplique-Plante (AP) e Manejo Antecipado (MA), em diferentes localidades do Estado do Paraná, em dez./2003 a mar./2004

\begin{tabular}{|c|c|c|c|}
\hline \multirow{2}{*}{ Localidade } & \multicolumn{2}{|c|}{ Sistema de manejo } & \multirow{2}{*}{ Médias } \\
\hline & $\mathrm{AP}$ & MA & \\
\hline & \multicolumn{3}{|c|}{ vagens planta ${ }^{-1}$} \\
\hline 1. Sertãozinho & 45,46 a & $33,48 \mathrm{~b}$ & 39,47 \\
\hline 2. Campo Mourão & 24,93 a & 27,69 a & 26,31 \\
\hline 3. Mamborê & 46,60 a & 51,01 a & 48,81 \\
\hline 4. Boa Esperança & $20,38 \mathrm{~b}$ & 32,92 a & 26,65 \\
\hline 5. Iretama & 39,58 a & 34,58 a & 37,08 \\
\hline 6. Pitanga & 52,08 a & 46,81 a & 49,45 \\
\hline Médias & 38,17 a & 37,75 a & - \\
\hline $\mathrm{CV}(\%)$ & 14,6 & - & - \\
\hline
\end{tabular}

Em cada linha, médias seguidas pelas mesmas letras não são diferentes entre si pelo teste de Tukey (5\%).

Tabela 9. Massa de mil grãos de soja submetida a dois sistemas de manejo de plantas daninhas Aplique-Plante (AP) e Manejo Antecipado (MA), em diferentes localidades do Estado do Paraná, em dez./2003 a mar./2004

\begin{tabular}{|c|c|c|c|}
\hline \multirow{2}{*}{ Localidade } & \multicolumn{2}{|c|}{ Sistema de manejo } & \multirow{2}{*}{ Médias } \\
\hline & $\mathrm{AP}$ & MA & \\
\hline & 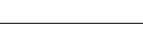 & $\mathrm{g}$ & +2 \\
\hline 1. Sertãozinho & $124,62 \mathrm{~b}$ & $132,70 \mathrm{a}$ & 128,66 \\
\hline 2. Campo Mourão & 130,82 a & 125,30 a & 128,06 \\
\hline 3. Mamborê & 127,11 a & 130,39 a & 128,75 \\
\hline 4. Boa Esperança & 97,78 a & 95,94 a & 096,86 \\
\hline 5. Iretama & 120,89 a & $122,29 \mathrm{a}$ & 121,59 \\
\hline 6. Pitanga & 130,21 a & $130,27 \mathrm{a}$ & 130,24 \\
\hline Médias & $121,91 \mathrm{a}$ & $122,82 \mathrm{a}$ & - \\
\hline $\mathrm{CV}(\%)$ & 4,9 & - & - \\
\hline
\end{tabular}

Em cada linha, médias seguidas pelas mesmas letras não são diferentes entre si pelo teste de Tukey (5\%). 
Outro efeito dos manejos de plantas daninhas no desenvolvimento final da cultura pode ser constatado nos dados apresentados na Tabela 10. Em $50 \%$ das áreas avaliadas, o teor de água nos grãos, por ocasião da colheita, era inferior naquelas em que se utilizou o sistema MA e em nenhuma das áreas o teor de água dos grãos no AP foi inferior ao do MA. Em média, nas áreas com AP os grãos estavam com $40 \%$ a mais de água. Como o método estabelecido neste trabalho pressupunha a colheita manual das parcelas, em ambos os manejos, não houve problemas nessa etapa, mesmo quando os teores de água foram maiores do que aqueles recomendados para a colheita mecânica. No entanto, é possível que a colheita tivesse que ser adiada no manejo AP, principalmente em Sertãozinho e Iretama, em função do teor elevado de água constatado nos grãos de soja. O maior nível de umidade é reflexo de atraso na finalização do ciclo das plantas e, em alguns casos, de reinfestação tardia nas áreas, o que não é constatado nas áreas com MA, em função do controle mais efetivo obtido em pós-emergência e do "fechamento" mais precoce nas entrelinhas da cultura da soja.

Verificou-se, em todas as localidades, redução da produtividade onde se adotou o manejo AP (Tabela 11). As reduções foram entre 15,2\% (Pitanga) e 50,0\% (Boa Esperança), referentes, respectivamente, a 9,9 até 17,5 sacos por hectare, quando comparado ao sistema MA. Esses resultados são semelhantes aos obtidos por OLIVEIRA JÚNIOR et al. (2006), que verificaram que no MA a soja produziu de 243 a $562 \mathrm{~kg}$ a mais por hectare, em relação aos sistemas AP e 10 DAS. No presente trabalho, as maiores reduções de produtividade foram verificadas nas áreas em Boa Esperança (17,5 sacas por hectare ou $50,0 \%)$ e Iretama $(12,1$ sacas por hectare ou $32,7 \%$ ).

Tabela 10. Teor de água nos grãos de soja, submetida a dois sistemas de manejo de plantas daninhas Aplique-Plante (AP) e Manejo Antecipado (MA), em diferentes localidades do Estado do Paraná, em dez./2003 a mar./2004

\begin{tabular}{|c|c|c|c|}
\hline \multirow{2}{*}{ Localidade } & \multicolumn{2}{|c|}{ Sistema de manejo } & \multirow{2}{*}{ Médias } \\
\hline & $\mathrm{AP}$ & MA & \\
\hline & & $\%$ & 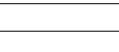 \\
\hline 1. Sertãozinho & 22,17 a & $11,67 b$ & 16,92 \\
\hline 2. Campo Mourão & 8,80 a & $9,00 \quad \mathrm{a}$ & 08,90 \\
\hline 3. Mamborê & 11,53 a & $7,25 \quad b$ & 09,39 \\
\hline 4. Boa Esperança & 6,67 a & 6,67 a & 06,67 \\
\hline 5. Iretama & 22,67 a & $15,83 \mathrm{~b}$ & 19,25 \\
\hline 6. Pitanga & - & - & \\
\hline Médias & $14,37 \mathrm{a}$ & $10,08 \mathrm{~b}$ & - \\
\hline $\mathrm{CV}(\%)$ & 19,7 & - & - \\
\hline
\end{tabular}

Em cada linha, médias seguidas pelas mesmas letras não são diferentes entre si pelo teste de Tukey (5\%).

Tabela 11. Produtividade de soja submetida a dois sistemas de manejo de plantas daninhas Aplique-Plante (AP) e Manejo Antecipado (MA), em diferentes localidades do Estado do Paraná, em dez./2003 a mar./2004

\begin{tabular}{lccc}
\hline \multirow{2}{*}{ Localidade } & \multicolumn{2}{c}{ Sistema de manejo } & Médias \\
\cline { 2 - 4 } & \multicolumn{1}{c}{$\mathrm{AP}$} & $\mathrm{kg} \mathrm{ha}^{-1}$ & 2882,94 \\
\cline { 2 - 4 } 1. Sertãozinho & $2575,80 \mathrm{~b}$ & $3190,07 \mathrm{a}$ & 2597,36 \\
2. Campo Mourão & $2353,12 \mathrm{~b}$ & $2841,59 \mathrm{a}$ & 3360,69 \\
3. Mamborê & $3023,89 \mathrm{~b}$ & $3697,48 \mathrm{a}$ & 1578,35 \\
4. Boa Esperança & $1051,90 \mathrm{~b}$ & $2104,80 \mathrm{a}$ & 1861,06 \\
5. Iretama & $1496,90 \mathrm{~b}$ & $2225,21 \mathrm{a}$ & 3591,85 \\
6. Pitanga & $3295,80 \mathrm{~b}$ & $3887,90 \mathrm{a}$ & - \\
\hline Médias & $2299,57 \mathrm{~b}$ & $2963,84 \mathrm{a}$ & - \\
CV(\%) & 17,1 & - & - \\
\hline
\end{tabular}

Em cada linha, médias seguidas pelas mesmas letras não são diferentes entre si pelo teste de Tukey (5\%). 
Durante a fase de enchimento de grãos, houve períodos de seca nessas áreas que foram as mais influenciadas pelos sistemas de manejo, sendo prejudicada a produtividade. Trabalhando com a cultura do milho, CONSTANTIN et al. (2007) verificaram que, independentemente do método de controle adotado em pós-emergência, com o manejo antecipado foram proporcionados ganhos de produtividade entre $696 \mathrm{e}$ $1867 \mathrm{~kg} \mathrm{ha}^{-1}$. Evidencia-se, assim, a importância do manejo de planta daninha utilizado antes da semeadura quando houver condições adversas durante o ciclo, possivelmente pela maior sensibilidade aos estresses em função da energia despendida no crescimento inicial. Desta forma, além da influência na incidência de plantas daninhas, também são afetados pelo sistema de manejo o desenvolvimento da cultura e a produtividade final. Neste trabalho, o sistema MA foi mais adequado ao manejo das plantas daninhas na cultura da soja em áreas com grande quantidade de cobertura vegetal estabelecida.

\section{CONCLUSÃO}

A redução na infestação de plantas daninhas, o desenvolvimento e a produtividade na cultura na soja são favorecidos no sistema de manejo antecipado de controle.

\section{REFERÊNCIAS}

BANZATTO, D.A.; KRONKA, S.N. Experimentação Agrícola. 3.ed. Jaboticabal: FUNEP, 1995.

CALEGARI, A.; HECKLER, J.C.; SANTOS, H.P.; PITOL, C.; FERNANDES, F.M.;HERNANI, L.C.;GAUDÊNCIO, C.A. Culturas, Sucessões e Rotações. In: Sistema Plantio Direto. O produtor pergunta a Embrapa responde. Dourados: Embrapa-CPAO. Dourados, 1998, p.59-80. (Coleção 500 perguntas 500 Respostas)

CONSTANTIN, J.; MACIEL, C.D.; OLIVEIRA JR., R.S. Sistemas de manejo em plantio direto e sua influência sobre herbicidas aplicados em pós-emergência na cultura da soja. Revista Brasileira de Herbicidas, Passo Fundo, v.1, n.3, p.233-242, 2000.

CONSTANTIN, J.; OLIVEIRA JÚNIOR., R.S.; CAVALIERI, S.D.; ARANTES, J.G.Z.; ALONSO, D.G.; ROSO, A.C.; COSTA, J.M. Interação entre sistemas de manejo e controle de plantas daninhas em pós-emergência afetando o desenvolvimento e a produtividade do milho. Planta Daninha, Viçosa, v.25, n.3, p.513-520, 2007.

EMBRAPA SOJA. Tecnologias de produção de soja - Paraná 2004. Londrina: EMBRAPA-CNPSoja, 2003. 218p.

MAROCHI, A.I. Avaliação de métodos de controle químico para Richardia brasiliensis (poaia-branca), infestando áreas sob plantio direto da Região Sul do Brasil. In: ZAPP: Desafio do novo. São Paulo: Zeneca Agrícola, 1996. p.175-186.
MELHORANÇA, A.L.; CONSTANTIN, J.; PEREIRA, F.A.R.; GAZZIERO, D.L.P.; VALENTE, T.O.; ROMAN, E.S. Plantas daninhas e seu controle. In: SISTEMA Plantio Direto. O produtor pergunta a Embrapa responde. Dourados: EmbrapaCPAO. Dourados, 1998, p.177-194. (Coleção 500 perguntas 500 Respostas).

MELHORANÇA, A.L; VIEIRA, C.P. Efeito da época de dessecação sobre o desenvolvimento e produção da soja. In: REUNIÃ̂O DE PESQUISA DE SOJA DA REGIÃO CENTRAL DO BRASIL, 21., 1999, Dourados. Anais... Dourados: Embrapa Agropecuária Oeste; Londrina; Embrapa Soja, 1999. p.224-225.

OLIVEIRA JÚNIOR., R.S.; CONSTANTIN, J.; COSTA, J.M.; CAVALIERI, S.D.; ARANTES, J.G.Z.; ALONSO, D.G.; ROSO, A.C. Interação entre sistemas de manejo e controle de plantas daninhas em pós-emergência afetando o desenvolvimento e a produtividade da soja. Planta Daninha, Viçosa, v.24, n.4, p.721-732, 2006.

PEIXOTO, M.F.;SOUZA, I.F.; SIQUEIRA, J.L. Efeitos de resíduos culturais de sorgo e doses de imazamox sobre a cultura da soja em plantio direto. In: CONGRESSO BRASILEIRO DA CIÊNCIA DAS PLANTAS DANINHAS, 22., 2000, Foz do Iguaçu. Anais... Londrina: SBCPD, 2000. p.95.

PINTO, J.J.O.; BORGES, E.S.; AGOSTINETTO, D. Manejo de herbicidas dessecantes no sistema de cultivo mínimo na cultura do arroz irrigado. In: CONGRESSO BRASILEIRO DA CIÊNCIA DAS PLANTAS DANINHAS, 21., 1997, Caxambú. Anais... Caxambú: SBCPD, 1997. p.165-166.

PROCÓPIO, S.O.; PIRES, F.R.; MENEZES, C.C.E.; BARROSO, A.L.L.; MORAES, R.V.; SILVA, M.V.V.; QUEIROZ, R.G.; CARMO, M.L. Efeito de dessecantes no controle de plantas daninhas na cultura da soja. Planta Daninha, Viçosa, v.24, n.1, p.193-197, 2006.

SAEG - Sistema para Análises Estatísticas, versão 7.0, Viçosa: Fundação Arthur Bernardes, 1997.

SOCIEDADADE BRASILEIRA DA CIÊNCIA DAS PLANTAS DANINHAS - SBCPD. Procedimentos para instalação, avaliação e análise de experimentos com herbicidas. Londrina: SBCPD, 1995. 42p. 